\title{
Inspiration from Antique Heroic Deeds: Hercules as an Astronomer
}

\section{Inga Elmqvist Söderlund}

\begin{abstract}
In the early modern period (during the Renaissance/Baroque eras) the comparison of the astronomer and his work to a Hercules or a Herculean Effort was not unusual. The learned and intellectual Hercules was described as an ideal and put forward as exemplary. This paper explores how the comparison was presented in text and image.
\end{abstract}

Hercules was one of the more popular ancient heroes in early modern European art. Palace decorations, paintings, engravings, bookillustrations, sculptures and other forms of art celebrate his endeavours in various forms. His life, like that of other ancient heroes, was used as inspiration, recounted as a story of an exemplary life. It could ideally be used by early modern man to serve as a role model, as a guide to lead a more virtuous life or as inspiration to work harder in order to achieve great accomplishments. The tragic main account of Hercules is of a man who, in a fit of madness, killed his own children and, to atone for this crime, undertook the famous tasks, the labours of Hercules, for which he is mainly known. This paper explores how Hercules was referred to in some astronomical books in seventeenth century Europe, particularly in imagery, dedications and related text. It explores how the mythical Hercules was an appropriate intellectual ideal, an exemplary ideal astronomer.

In modern popular culture, for example in films from the last decades, Hercules' immense physical strength is emphasized, whereas his allegedly intellectual endeavours are not explored. $\mathrm{He}$ has, in our understanding, become the opposite of an intellectual, or a man of literary culture. Perhaps this is due to the circumstance that it is rather unlikely for a man to be able to at once cultivate both excessive physical strength and excessive learning. To build up muscles takes time and so does the acquisition of intellectual learning. The muscular bodybuilder is, according to modern standards, hardly a likely and probably not trustworthy personification of an academic or philosophy-minded personality. It seems probable that someone spending a lot of passionate

Inga Elmqvist Söderlund, 'Inspiration from Antique Heroic Deeds: Hercules as an Astronomer', eds. Nicholas Campion and Rolf Sinclair, Culture and Cosmos, Vol. 16 nos. 1 and 2, 2012, pp. 139-150.

www.CultureAndCosmos.org 
time in a library reading books, observing with the telescope, or making complicated calculations is less likely to succeed as a bodybuilder. The hero of Disney's movie Hercules (1997) is determined, strong and fairminded. Even if the film briefly refers to celestial matters (planetary alignments and constellations), the character of Hercules is not typical material for an astronomer-mathematician-philosopher. He wins in the end only because of his extraordinary strength and good heart. Disney's Hercules has little in common with the Hercules referred to in early modern astronomy books.

I do not claim that the image of the muscular and violent Hercules did not exist in early modern Europe, because there are numerous examples of works of art depicting Hercules involved in heroic violence, displaying his enormous physical strength. There seem to have existed different ideas of the concept of Hercules at this time: on the one hand a man of massive muscles, involved in violent acts; on the other a courtly and intellectual figure, an image also connected to the ideal astronomer. In this paper I wanted to pursue the relationship between physical strength, moral strength and learning. I have chosen to look at front matter in books on astronomy from the $17^{\text {th }}$ century. In forewords, dedications, poems, introductions, title pages and illustrations we find important information about whom the book is directed to, and how it is intended to be read. The front matter can be seen as the entrance to the book. The images of the frontispiece or the illustrated title-page can be seen as a parallel to the frontispiece of a building, where the façade at the entrance is supposed to externally represent the content and provide an appropriate exterior. ${ }^{1}$ The name of Hercules is often mentioned in the dedications and forewords, particularly as the author praises his princely dedicatee, but also as a reference to the astronomer himself.

\section{Hercules, the Student of Astronomy}

On the illustrated title page of Johannes Bayer's Atlas on the constellations, Uranometria (1603) the theme of Hercules as a student of astronomy is put forth. A number of ancient figures are placed on an architectural structure. Above left is Apollo, the sun and the dragon killer (the dragon is beneath his foot, also the lyre and the bow), to the left is

1 On front matter in general, see G. Genette, Paratexts: Thresholds of interpretation (Cambridge: Cambridge University Press, 2001); see also for illustrations: I. Elmqvist Söderlund, Taking possession of astronomy (Stockholm: The Royal Swedish Academy of Sciences, 2010). 
Artemis (Luna/Diana) with bow and arrows and a hunting-dog, clad in a dress studded with stars, and with the moon on her brow. Here they simultaneously represent sister and brother, sun and moon, day and night. In the middle is a crowned woman representing Eternity holding a branch of a palm tree, in a coach drawn by a lion and a lioness. Below is a view of Augsburg, and just above the city is an image of Capricorn, most likely a reference to Augustus, the Roman emperor who gave the city its name. There is also to the left Atlas, an old, bearded, turbaned man in ancient garb, with an astrolabe and a pair of compasses. To the right with his traditional attributes is Hercules.

Uranometria was a successful book and it was reprinted in several editions in different format, both with and without illustrations. ${ }^{2}$ Almost 2000 positions of stars are stated. Bayer used the observations of Tycho and other new observations - for example of the southern skiesand introduced a system of classification with Greek and Latin letters, stated in order of apparent brightness. The lore and history of the constellation is also given, with numerous references to texts and artefacts. This was the kind of information that an astronomer at the time was expected to be familiar with, particularly the ancient literary sources. The book contained precise plates with illustrations of the constellations made by Alexander Mair, which contributed to its popularity. Each constellation is shown within a grid with coordinates which make it possible to read the position of the star.

As Hercules is also a constellation it could be questioned whether the constellation of Hercules is alluded to on the title page. However the constellation of Hercules, also depicted on a large plate within Uranometria is, as tradition bids, depicted as a kneeling figure, Engonasin. On the title page Hercules is depicted in a position which is very different. He is easily recognizable through his usual attributes: the lion's skin and the knobbly stick, standing carrying the globe of the heavens. This globe is a reference to the episode where Hercules tricked Atlas to aid him in one of his labours, to fetch the Apples of the Hesperides. But in this image there are no apples. Here the carrying of the globe has another implication. The many myths around Hercules had grown during the centuries and there were variants praising his different

2 Digitised editions are available at Linda Hall Library: http://www.lindahall.org/services/digital/staratlases.shtml and Istituto e Museo di Storia della Scienza: http://fermi.imss.fi.it/rd/bd?lng=en. 
virtues. ${ }^{3}$ In some versions he became a student of astronomy. According to one variant on the myth of Atlas, he was a prince who knew astronomy and astrology. He discovered the nature of the sphere, hence the myth that he carried the heavens. Further, the carrying of the globe, the heavy burden, could also denote both the responsibility of the astronomer and that it was difficult to learn the art of astronomy and geometry. In one version Hercules saved Atlas' daughters from pirates and, as thanks, is taught astronomy. During the Renaissance this story was further elaborated in the Recueil des hystoires de Troyes by Raoul le Fèvre (1464-69), from which a particular romance of Hercules was later separately published. In this romance it is recounted that Hercules visited King Atlas close to Libya. Hercules was taught all the sciences, and because he learned and understood very quickly he was soon the most accomplished philosopher/astronomer in the world. After many adventures they travelled together to Athens, where Hercules excelled in astronomy. ${ }^{4}$ Inscriptions on the frontispiece make sure that Atlas and Hercules would be recognized and associated with this particular storyline: 'Hercvli vetvstiss[imo] astronom[iae] discipvlo' (To Hercules, the most ancient student of astronomy) and 'Atlanti vetvstiss[imo] astronom[iae] magistro' (To Atlas, the most ancient teacher of astronomy).

To further strengthen the connection to the ancient philosophers of Athens and learning, there is a Greek inscription 'OY $\Delta \mathrm{EI} \Sigma \mathrm{EI} \Sigma \mathrm{IT} \Omega$ АГЕ $2 M E T P H T O \Sigma$ ' (Let no one enter here who is ignorant of geometry). This was allegedly written over the entrance to Plato's academy. It confirms that astronomy is dependent on geometry and mathematics, and also defines the clientele of the book. ${ }^{5}$ A variant of the same phrase was

${ }^{3}$ M.R. Jung, Hercule dans la littérature Française du XVIe siècle (Geneva: Droz, 1966). I would particularly like to thank Prof. Hans Helander for valuable comments. See also V. Remmert, Widmung, Welterklärung und Wissenschaftslegitimierung (Wiesbaden: Harrassowitz, 2005). Further references in J.H. Zedler, Grosses vollständiges universal Lexicon aller Wissenschafften und Künste (Halle \& Leipzig: J. H.Zedler 1732-1754), Vol. 2 col. 2046 ff (Atlas), Col. 12 col. 1644 ff. (Hercules).

${ }^{4}$ Jung, Hercule, pp. 16, 21, 23.

5 On this frontispiece, see W. Ashworth 'Divine reflections and profane refractions', in I. Larvin (ed.), Gianlorenzo Bernini: New Aspects of His Art and Thought. A Commemorative Volume. (University Park, PA: Pennsylvania State University Press, 1986), p. 180, and Remmert, Widmung. 
also printed on the title page of Copernicus's De Revolutionibus (1543). It is of course possible that the inclusion of this inscription was an indirect reference to Copernicus, but it is more likely a more general indication that the book contains the heritage of ancient learning. ${ }^{6}$ Geometry, together with ancient languages, was part of the knowledge that the reader was supposed to master. Considering the many illustrations of the book, it can however be expected that many of its users would not belong to the learned elite. The inscription can also be seen as a kind of declaration of content, and seems to promise the reader that, in reading the book, he will gain some connection to the learned heritage of the past.

The motif of Hercules and Atlas is recurrent on some frontispieces. In another design it is also presented on the frontispiece of Andrea Argolis's Ephemerides (1648). Here Atlas and Hercules are carrying the globe of the heavens together. They are presenting the globe in such a manner that it allows for Urania to demonstrate the use of compasses on it. There is no obvious conflict or trickery, as in the main story of Atlas and Hercules, in this picture. Here the apples of the Hesperides have become the metaphor for the learning of the geometry of the sphere and astronomy. The scene has a pleasant atmosphere where learning is a tableau where all three players seem to enjoy the fruits of learning, in which teaching and learning have become a pleasant pastime. In baring parts of her body, Urania is showing some of her secrets, similar to the personification of Truth, who is normally depicted naked. She is accompanied by a small putto and an armillary sphere, possibly an intended similarity to the goddess of love, Venus, here indicating celestial love.

How widespread was this notion of Atlas and Hercules as astronomers in the early modern period? In astronomical texts his name often occurs, particularly in dedications and in praising the dedicatee. Atlas however is far more common, at least in front-matter imagery in astronomical books. ${ }^{7}$ One beautiful example of Atlas on a frontispiece is found in the small format book of Jakob Bernoulli, Dissertatio de

\footnotetext{
${ }^{6}$ E. Rosen p. XV in Copernicus, N., De Revolutionibus orbium coelestium, Vol. II, trans. E. Rosen, (Baltimore: The Johns Hopkins University Press, 1978); Elmqvist, Taking possession, p. $298 \mathrm{f}$.

${ }^{7}$ Adam Mosley has pursued the connotations of Atlas to astronomers and astronomy in the early modern period in his book Bearing the Heavens: Tycho Brahe and the Astronomical Community of the Late Sixteenth Century (Cambridge: Cambridge University Press, 2007).
} 
Gravitate Aeteris (Amsterdam 1683). Here Atlas is depicted as a lonely colossus, bent and tired under the heavy burden of the vault of heaven. $\mathrm{He}$ is standing on the rounded earth on some rocks, indicating the Atlas Mountains in Africa. The sun is just rising, allowing us to see his figure, but Atlas seems not to stir. Here the burden of the heavens and of learning is everlasting, difficult to bear, just like the responsibilities of a learned man. In this image, in comparison to the example in Argolis's frontispiece, the learning of the heavens is not light and pleasant, even if it is awesome. The burden of the learned man is exemplified in the character of the learned Hercules or Atlas.

Many astronomical books of the $17^{\text {th }}$ century start by recounting the ancient history of the subject, often as far back as in Biblical or Mythical time. Placing the subject in history and extolling the relevance of the subject to the most ancient of known humans was part of how astronomy was presented. An interesting list of astronomers is found in Edward Sherburne's The sphere of Marcus Manilius made an English poem (1675). Sherburne was an English poet and translated the astronomical and astrological poem Astronomicon by the Roman poet Marcus Manilius from the first century AD into English. This book contains more than just a translation. It is also an extensive book on contemporary astronomy. One of the chapters contains a list, 'A catalogue of the most eminent astronomers, ancient and modern'. It lists both Hercules and Atlas. ${ }^{8}$ It starts with Adam, and continues in chronological order with Seth. Among obvious names, such as Ptolemy, are also found Abraham, Moses, Solomon, Caesar, Ovid and many more. Atlas is mentioned briefly as king of Mauretania, inventor of the sphere, and is hence said to have carried the heavens on his shoulders. The version of Atlas being a teacher to Hercules is not mentioned by

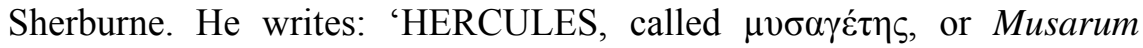
ductor, to distinguish him from the other Hercules, was so well learned in the Doctrine of the Sphere, that he is therefore feigned to have eased Atlas of his burden; whence Ovid, Hercule supposito Sydera fulsit Atlas'. ${ }^{9}$ Hercules is specified as leader of the muses, the peaceful

\footnotetext{
${ }^{8}$ E. Sherburne, The sphere of Marcus Manilius made an English poem: with annotations and an astronomical appendix (London: The Sphere, 1675). A digitized version is available at Istituto e Museo di Storia della Scienza: http://fermi.imss.fi.it/rd/bd?lng=en.

${ }^{9}$ Ibid $\mathrm{p} 8$ in the section A catalogue of the most eminent astronomers, ancient and modern.
} 
Hercules, leader of the arts and sciences. The text specifies that this Hercules is distinguished from the other one. Here is a notion, with which some historians disagree, that the ancient myths could not possibly concern one and the same person. It is also specified that Hercules excelled in geometry, and Sherburne relates the episode in which Hercules relieved Atlas of the burden of the celestial sphere. The quote at the end is from Ovid's Heroides, Deianeira's letter to Hercules, and alludes to the moment when Hercules carried the heavens on his shoulders.

The many-faceted face of Hercules made him a very useful figure who could fit into many Early Modern contexts, one of them astronomical. Whether the same or a different Hercules, the resemblance between a famous ancient hero and a student of astronomy, he could be used as an example with which to explore the subject. Potentially the student of astronomy could feel inspired that his study was not in vain but meaningful, and also heroic. The labour of study was part of a virtuous and heroic example of an exemplary ancient life.

\section{Hercules at the Crossroads}

A popular motif of Renaissance literature and art was Hercules at the Crossroads. ${ }^{10}$ The motif is based on ancient sources and refers to Hercules as a young man, at the crossroads. There he encounters two fair women, one of them promising a life of virtue, the other vice. In art the motif usually shows Hercules seated in the middle, tormented by his difficult choice, flanked by two beautiful women, one of them modest and the other voluptuous. Whereas Virtue does not conceal the fact that her way is both arduous and long, Vice promises a short road of enjoyment and pleasure. In the end Hercules is convinced by the arguments of Virtue.

I could not find any imagery depicting this episode in front matter of astronomical books of the seventeenth century, but the episode is referred to in text in connection to the great philosophical issue of whether or not the sun moves. On the frontispiece of Giambattista Riccioli's Almagestum Novum, printed in Bologna in 1651, the order of the solar system is the main theme. ${ }^{11}$ This book presents a general

\footnotetext{
${ }^{10}$ W. Harms, Homo viator in bivio: Studien zur Bildlichkeit des Weges (Munich: Medium aevum: Wilhelm Fink, 1970); E. Panofsky, Hercules am Scheidewege und andere antike Bildstoffe in der neueren Kunst (Leipzig: B.G. Teubner, Studien der Bibliothek Warburg, 1930).

${ }^{11}$ For more frontispieces on this theme, see Remmert, Widmung.
}

Culture and Cosmos 
overview of astronomy at the time and seems to have been successful because a second edition was printed just two years later. The intriguing frontispiece addresses issues dealt with by the author, and contains several figures and many quotes from the Bible and other ancient sources, such as from Ovid. The scene is set in a landscape. To the left is Argus, the giant whose body is covered with eyes, which could be seen as a metaphor of the heavens, and to the right Astraea, the pure and celestial virgin. She holds a weighing scale with two systems, one heliocentric, the other geoheliocentric. The latter is the author's own variant of the Tychonic. At her foot is the ancient geocentric system. Above them, centrally placed, is the hand of God, and on its sides are putti-cupidscarrying the celestial bodies, to the left the sun with the bodies circling it, and to the right the night with the celestial bodies circling the earth (according to the author). Ptolemy, lying down, rests his one hand on the Grimaldi coat of arms, and his other arm on a shield.

The title of the book, The New Almagest is an allusion to Ptolemy's Almagest and is a tribute to the legacy of classical astronomy. The author has described and partially explained the frontispiece in the two dedications found at the beginning of the first and second volumes and dedicated separately to two different members of the Grimaldi family. He explained the odd feature of Argus holding a telescope directed towards an eye on his knee in the following manner: 'There Argus with all his eyes, no with the entire eye, moves the telescope rather to his knee (genu) than to the eye of his cheek (genae) not so much sees the outstanding work of Gods fingers, as he reveres them while being about to kneel'. ${ }^{12}$ Astraea, weighing the systems, notices a 'Welldesigned levity in the mobility of the world, and in the immobility an inclining judgment. She [Astraea] finds that saying from David very likely, which once had resounded from heaven into her own ears: it should not be removed forever'. ${ }^{13}$ The text points out that whether the earth is moving or not is a matter of judgment, and that the Bible should be considered. The text refers to the controversy as an analogy to Hercules at the crossroads. Here the act of choosing a system is put forwards as a matter of virtue: 'But now it was suitable that the system of the world, and the entire burden of this controversy, was preserved by the

12 G. Riccioli, Almagestum Novum, Vol. II Dedication to Honoratio II, unpaginated (Bologna: Haeredis V. Benatius, 1651), a digitized version is available at: http://gallica.bnf.fr/ark:/12148/bpt6k51332p.image.f3.pagination. For a translation by Peter Sjöqvist, see Elmqvist, Taking possession, p. 380.

Culture and Cosmos 
authority of this prince, who would sustain Hercules' lot with hereditary justice'. ${ }^{13}$ The price referred to is the Grimaldi dedicatee, and the reference to Hercules has various indications. Hercules represents at once the ancient hero and the deceased father of the dedicatee. The princededicatee is placed at the crossroads, like Hercules, and his choice is between the two systems. This was one of the challenges the early modern astronomer-philosopher would face. Just like the tormented Hercules at the crossroads, the prince-astronomer would have to make up his mind on this complicated issue. On the frontispiece of Riccioli's book the virtuous woman Astraea acts as Virtue herself, not unlike the constellation Virgo, aiding the beholder/reader to judge in favour of the virtuous geoheliocentric model.

The fact that the frontispiece was explained in the dedications, and that the author asked the prince to 'turn one and another page for a while, and study the picture that is on the front-side of the work' indicates that the author intended that the reader should look thoroughly at the frontispiece and consider its meaning for a while. ${ }^{14}$ There are many layers of meaning in the picture, an indeterminacy, and many possible threads suitable for interpretations and learned digression. Riccioli's own texts are not explicit concerning all the details or possible allusions in the references, which is part of its appeal. The picture and accompanying text make clear that learning astronomy comprised not only knowledge about celestial matters, but also the ancients, theology and not least a moral development, which would enable one to judge in philosophical matters.

\section{The Labours of Hercules}

In the front matter of Johannes Kepler's Rudolphine tables (1627) the labours of Hercules were used as a simile for the immense effort involved in producing an astronomical work. The tables contained the information from Tycho's observations for the stars and planets, and were a work Kepler had been struggling with for years. It was the result of countless hours of hard labour. The very interesting frontispiece has a rather intricate pictorial programme, and is described in a 450-hexameter poem written by the Latinist Johannes Hebenstreit (Figure 1). In short, the frontispiece depicts the temple of astronomy in which a number of astronomers of different eras are gathered for a philosophical discussion.

\footnotetext{
${ }^{13}$ Elmqvist, Taking possession, p. 380. The Biblical quote from David is from Ps. 104, 5.

${ }^{14}$ Elmqvist, Taking possession, p. 380.
} 
148 Inspiration from Antique Heroic Deeds: Hercules as an Astronomer

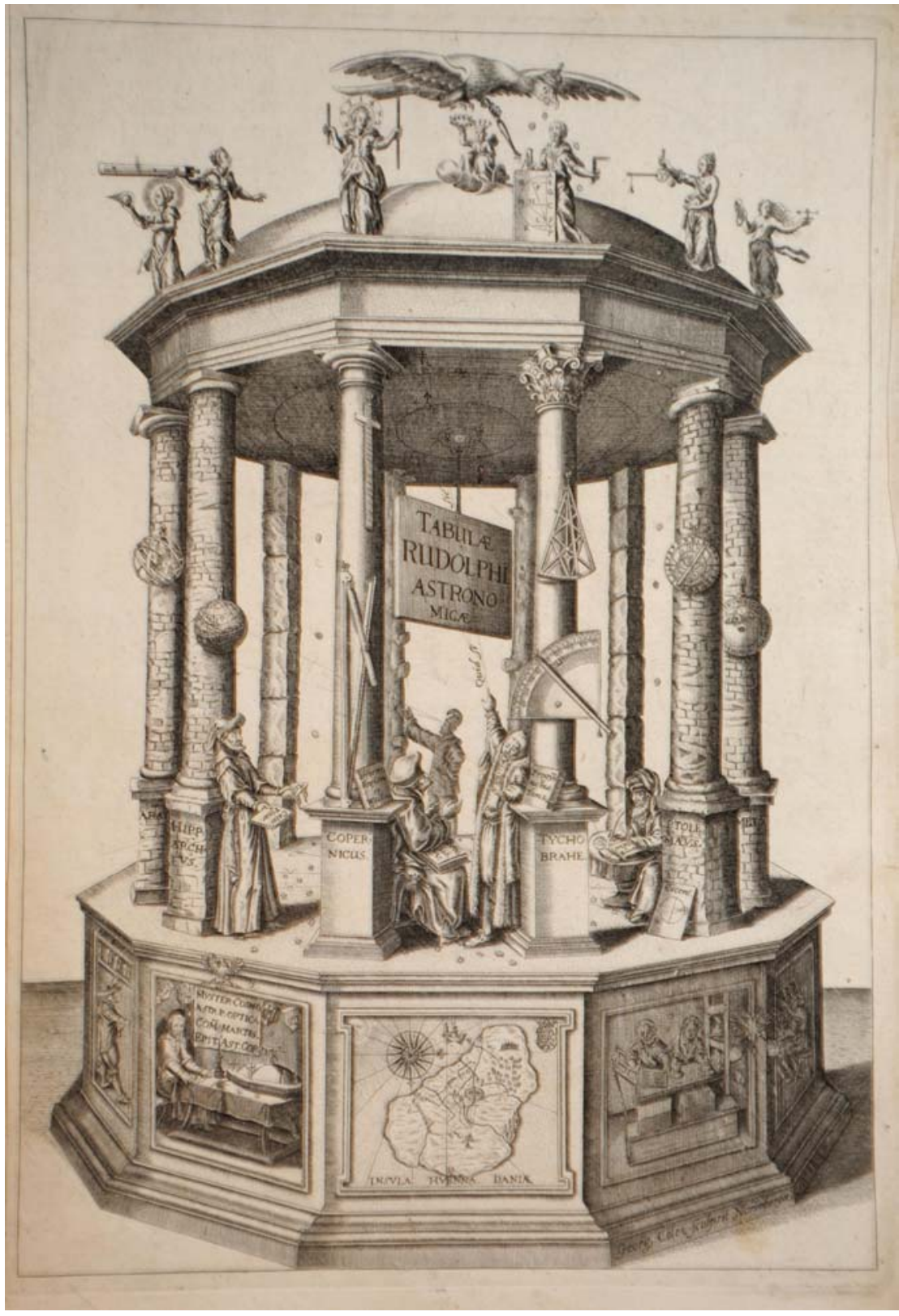

Figure 1. Frontispiece of Johannes Kepler's Rudolphine tables (1627) 
Centrally at the front Tycho and Copernicus are engaged in a dispute on whether the sun is moving or not. Tycho is pointing towards the ceiling where his geoheliocentric system is inscribed, speaking 'Quid Si Sic' (If it were so). On the base of the temple are framed scenes with different motifs, in the middle the island of Vhen, and on the sides scenes depicting events related to the production of the book. On top of the temple female figures represent the different branches of relevant sciences. Visible are Magnetica, Stathmica, Doctrina triangulorum, Logarithmica, Optica, and Physica lucis. These ladies are put there as servants to Urania, placed at the top of the temple. Above it the imperial eagle sprinkles coins from its beak. ${ }^{15}$

Hercules is not part the pictorial programme, but the poem mentions the labours of Hercules in relation to Kepler. Kepler is depicted to the left on the base of the temple. He is sitting at a table on which is placed a structure representing his work, a miniature model of the top of the temple with the female figures. In front of him his most important works are listed. His life's accomplishments are presented in this scene. The poem puts it like this, as if Kepler was watching the play enacted above in the temple: 'He sits, weighing the disputes of the discussing men in a careful examination. But he feels more close to the seat of learning of Prussia [that is Copernicus] and carefully listens to their argument, and he grazes on the connected warps of the continuous night, inflaming them with his intellect. What he himself has done, as an equal to labouring Hercules, as long as the work was still advancing, the walls and the books relate, and above all the tablets themselves. ${ }^{16}$ Kepler's heliocentric preference comes through, and at the summit of his life he is portrayed as a knowledgeable judge in this difficult philosophical issue.

There are no similarities between Kepler's physical appearance and that of the muscle man Hercules. The resemblance lies in the immense effort and strength demanded to finish the labour. Kepler's lean body is marked by the long hours of endless calculations and writing. The battles he has fought were not against physical monsters but false theses

\footnotetext{
${ }^{15}$ For a complete description of the frontispiece see either J. Kepler, Gesammelte Werke Vol. X, part VIII (Munich: C.H. Beck, 1969) or for a translation into English in Elmqvist, Taking possession pp. 370-375. The frontispiece is extensively published, see the following works for further references: S. Gattei, 'The Engraved Frontispiece of Kepler's Tabulae Rudolphinae (1627): A Preliminary Study', Nuncius: annali di storia della scienza, No. 2 (2009), and Elmqvist, Taking possession.

${ }^{16}$ Elmqvist, Taking possession, p. 374.
} 
and academic adversaries. The writing desk is the proper place where the astronomer-mathematician can accomplish his labours. Considering that Kepler's work is compared to Hercules' labours in the poem, it might seem surprising that his placing is rather inferior, to the side at the base of the temple. However, for the design of the frontispiece Kepler had to take into consideration the heirs of Tycho, who had several objections to the original design. In fact, they were very conscious about how Tycho appeared, in minute detail, such as his clothes. ${ }^{17}$ It is, however, possible that this detail went unnoticed, as Copernicus is not mentioned by name, however obvious the allusion to the Prussian man. Albeit the inferior position in the picture it is, according to the poem, Kepler who, through his hard work is in the appropriate position to judge the dispute between Tycho and Copernicus. His judgment, after carefully examining all arguments, is inclined towards Copernicus's system. So here the work of the astronomer is considered as arduous as the incredible labours of Hercules, as equal to the labouring Hercules, not in terms of his physical body, but in the immense mental effort and difficult choices the astronomer faces. Here Kepler, the successful student of astronomy has, through Herculean labours, reached a conclusion at the crossroads, much like the great ancient hero. He has shown not physical strength, but exceptional steadfastness and virtue. In this way Hercules was an appropriate intellectual ideal of an Early Modern astronomer.

${ }^{17}$ F. Hammer, 'Nachbericht', in Kepler, Gesammelte Werke, Vol. X (1969), part VIII.

Culture and Cosmos 